\title{
Max Weber na Sociologia Argentina $(1930-1950)^{*}$
}

\author{
Alejandro Blanco
}

$\mathrm{E}$ m 1944, o Fondo de Cultura Económica protagonizou um feito surpreendente no contexto da história das ciências sociais na América Latina. Nesse ano, ju stamente, lançou a primeira versão integral em língua estrangeira de Economía y Sociedad, a obra de maior fôlego teórico de Max Weber ${ }^{1}$. Dois anos antes, a mesma editora havia publicado Historia Económica General desse autor. Em meados da década de 40, no entanto, esse começo editorial promissor se interromperia. De fato, tal como se deduz da informação reunida no apêndice, esse primeiro momento de ascen são foi seguido de um intervalo de uns vinte anos, durante os quais praticamente não se empreenderam traduções e tampouco reimpressões. A segunda edição de Economía y Sociedad ap areceu vinte anos mais tarde, em comemoração do primeiro centenário do nascimento do autor. Em meados dos anos 60, e já como parte de um fenômeno mais abrangente, relativo à importância que foi ganhando Weber nos Estados Unidos, em um primeiro momento, e na Europa, mais tarde (Shils, 1970; Schroeter, 1980; Pollak, 1986; Käsler, 1988; Kivisto e Sw atos, 1988; Hirschhorn, 1988), sua obra voltou a estar no centro da atenção das principais editoras de língua espanhola. Um fenômeno similar pode ser observado na língua por-

*[A tradução do original em espanhol "Max Weber en la Sociología Argentina (19301950)" é de Renata Oliveira Rufino.] 


\section{Alejandro Blanco}

tuguesa, para o caso específico do Brasil, que registra as primeiras traduções na segunda metade dos anos 60 (Lima, 1987).

Mas, independentemente das razões que possam ser alegadas para explicar essa curva experimentada pelas edições de Weber em língua espanhola, o próprio feito editorial abre, a princípio, uma série de questões relativas aos modos de circulação, difusão e recepção de sua obra tanto na América Latina em geral quanto na Argentina em particular: que repercussões teve essa primeira edição de Weber em espanhol? quem se interessou por sua obra e por quê?

$\mathrm{Na}$ Argentina, tais questões se tornam aind a mais interessantes quando colocadas no contexto de um dado bastante sugestivo: Weber já era conhecido antes das primeiras traduções para o espanhol. Em 1932, Raúl Orgaz ded icaria u m capítulo de La Ciencia Social Contemporánea a um exame de su a obra (Orgaz, 1932a). Nove anos mais tarde, Alfredo Poviña publicou La Metodología Sociológica de Max Weber (Poviña, 1941a) e, nesse mesmo ano, Renato Treves (1941) ocupou-se de Weber em Sociología y Filosofía Social. En fim, que sua figura era relativamente conhecida fica patente no comentário que Roberto Fraboschi fez no Boletín del Instituto de Sociologíana época do lançamento de Economía y Sociedad. De fato, como querendo desculpar a pálida e sucinta resenha concedida ao livro, Fraboschi reconhecia que "esta obra já é suficientemente conhecida através de notas e comentários. Limitamo-nos, portanto, a dar a simples notícia do a parecimento em espanhol deste estudo que há de interessar aos estudiosos em ciências sociais" (1944:364). Finalmente, e também a propósito do surgimento de Economía y Sociedad, Francisco Ayala dedicou dois artigos a Weber no jornal La Nación (Ayala, 1947).

Os autores mencionados eram professores de sociologia nas principais universidades argentinas. Todos eram, por sua vez, membros do conselho de uma instituição consagrad a aos estudos sociológicos, o Instituto de Sociologia da Faculd ade de Filosofia e Letras da Universidade de Buenos Aires, criado por Ricardo Levene em 1940. Portanto, foi entre os sociólogos, ou melhor, no campo da sociologia universitária, e não entre os filósofos ou os historiadores, que a obra de Weber despertou interesse e encontrou seus primeiros intérpretes. Mas, qual Weber? O proponente de uma nova visão da ciência social? O teórico da racionalização? O porta-voz de uma sociologia compreensiva? O 
arauto de uma renovada concepção da ação humana? O expoente de uma sociologia histórica comparada?

Dado que a recepção de um autor está sempre associada, de um modo ou de outro, aos projetos e apostas intelectuais e científicas de seus diferentes receptores, todo fenômeno de recepção é inevitavelmente seletivo. Conforme a natureza e o alcance desses projetos e apostas intelectuais, determinados campos temáticos serão privilegiados em lugar de outros. E então, em torno de que campos temáticos e com que projetos teóricos esteve sintonizada essa primeira recepção de Weber na Argentina? O estudo das referências a um autor estrangeiro como observado por Michel Pollak - costuma se transformar em um revelador das tensões e dos pólos que estruturam as linhas de força de um determinado campo intelectual (Pollak, 1986). As primeiras referências a Max Weber na Argentina apareceram em um momento em que a sociologia era, ainda, uma disciplina em formação e, como tal, desejosa de afirmar sua legitimidade intelectual no sistema universitário. Diferentes concepções acerca de suas tarefas, assim como de seus métodos, estavam em discussão naquela ocasião. Foi, precisamente, nesse contexto que a obra de Weber esteve no centro da atenção dos professores de sociologia e chegou a se converter em objeto de disputa entre os primeiros comentaristas. Neste trabalho examinarei, então, as características que a recepção de Weber assumiu na Argentina durante esse período formativo da disciplina e tentarei mostrar de que maneira a mudança na interpretação de seus ideais intelectuais esteve na origem de uma nova interpretação daqueles aspectos de sua obra que foram objetos de comentário.

\section{DIFUSÃO EDITORIAL E ENSINO UNIVERSITÁRIO}

Em 1934, Ricardo Levene, na época professor titular de sociologia da Faculdade de Filosofia e Letras da Universidade de Buenos Aires, apresentava a edição espanhola de Filosofía de la Sociedad y de la Historia, de Alfred Vierkandt, nos seguintes termos:

“Os estud os de sociologia exigem especialização filosófica e jurídica. Tal d isciplina e seu amplo desenvolvimento são o domínio abarcado pelo sociólogo autêntico, substituindo cientificistas e pragmatistas, que declamam sobre o império das leis naturais absolutas regendo as sociedades humanas como a natureza e confundem seu conteúdo com uma espécie de medicina social" (Levene, 1934:2). 


\section{Alejandro Blanco}

Essas palavras resumem, de algum modo, as preocupações que dominaram os meios filosóficos e sociológicos durante a década de 30, caracterizando o contexto intelectual da época com aquilo que se chamou de reação antipositivista de cunho "espiritualista" (Romero, 1952). Um aspecto dessa reação, como se sugere a partir das afirmações de Levene, esteve constituído pela importância atribuída à filosofia e ao direito na compreensão e interpretação da vida social, perante o privilégio conferido pelo positivismo às ciências naturais - especialmente à biologia. No novo clima intelectual, os direitos do espírito antepunham-se a um cientificismo materialista e mecanicista cuja aproximação naturalista à vida social, conforme se argumentava, terminava reduzindo todo o referente ao comportamento humano às férreas leis da matéria. Ao mesmo tempo, questionava-se a pretensão positivista de transferir métodos, que só resultavam válidos para analisar o mundo material, para o domínio do subjetivo que, não quantificável por natureza, deveria ficar submetido a um tipo de saber que fosse capaz de ressaltar a autonomia da personalidade.

No contexto dessa reação positivista, e especialmente nos meios filosóficos, a cultura alemã transformou-se em uma referência central para a crítica ao positivismo. Dilthey, Husserl, Heidegger e Hartmann contaram-se entre os filósofos mais freqüentados. A Revista de Occidente e a Biblioteca de Ideas del Siglo $X X$, ambas sob a direção de Ortega y Gasset, constituíram-se nos canais mais significativos de ingresso e difusão da cultu ra alemã nos círculos acadêmicos (López Campillo, 1972). A editora da Revista de Occidente publicaria, entre 1924 e 1936, uns 205 títulos distribuídos entre as vinte coleções com que contava. A Nuevos Hechos, Nuevas Ideas, a mais importante no domínio da filosofia e das ciências sociais, editou 39 títulos entre 1925 e $1935^{2}$.

Um efeito derivado dessa abertu ra à cultura alemã foi a implantação editorial da sociologia alemã na Argentina. De fato, já desde a déca da de 20 , mas com maior intensidade a partir dos anos 30 , as traduções de obras de sociólogos alemães experimentam uma expansão notá$\mathrm{vel}^{3}$. A partir da década de 30 , por sua vez, a sociologia alemã começou a ganhar importância nos trabalhos de nossos professores de sociologia. Raúl Orgaz escreveu sobre Simmel e Vierkandt (Orgaz, 1932b) e dedicou três capítulos de seu livro La Ciencia Social Contemporánea a um exame da ciência social na Alemanha, no qual incluiu seu ensaio sobre Max Weber (Orgaz, 1932a). Em dois ensaios publicados 
em Cursos y Conferencias, Alfred o Poviña tratou sobre Simmel, Vierkandt e Von Wiese (Poviña, 1933a; 1933b). Por volta dos anos 40, a atenção deslocou-se em direção a Hans Freyer e Max Weber (Poviña, 1939; 1941a e Treves, 1941).

Essa implantação editorial da sociologia alemã logo se faria notar tanto no ensino da disciplina como nos modos de sua recepção. De fato, se até essa época os nomes que estão no centro da atenção de nossos professores de sociologia são os de Herbert Spencer, Augusto Comte, Franklin Giddings, Émile Durkheim e Gabriel Tarde, por volta da década de 30 os programas de ensino incorporam leituras de G. Simmel, L. von Wiese, A. Vierkandt, R. Stammler, M. Scheler, O. Spann, F. Toennies, H. Freyer, K. Mannheim e M. Weber. Algo não muito diferente pode ser observado nos programas de sociologia de outros países da América Latina (Poviña, 1941b).

Por sua vez, e como parte daquela reação antipositivista anteriormente mencionada, a autocompreensão "positivista" $d$ a sociologia vigente até as primeiras décadas do século XX se viu desbancada por uma autocompreensão "culturalista", que pressupunha o traçado de uma rígida fronteira entre a pesquisa empírica ou sociografia e a sociologia pu ra ou ciência da cultura. De acordo com essa nova visão, sobre a qual existia um relativo consenso entre os praticantes da disciplina, a sociografia, guiada por métodos naturalistas, era concebida como disciplina au xiliar da sociologia; a esta ficava reservada a tarefa de conhecer aquela dimensão da vida social que, dada sua natureza eminentemente espiritual, exigia uma aproximação nos termos de uma compreensão intuitiva.

De algum modo, o período em que a sociologia alemã se integra aos programas de ensino da sociologia coincide com essa abertura e implantação ed itorial da cultura alemã na Argentina. A partir de então, e até o final dos anos 40, a sociologia ale mã converter-se-ia no universo de referên cia quase exclusivo entre os praticantes da disciplina. Uma prova eloqüente disto é o fato de que em 1938 Alfredo Poviña obtém o cargo de professor- assistente de sociologia na Faculdade de Filosofia e Letras da Universidade de Buenos Aires com um extenso escrito sobre Hans Freyer, intitulado La Sociología como Ciencia de la Realidad (Poviña, 1939). 


\section{Alejandro Blanco}

Certamente, aind a que chamativa, essa propagação d a sociologia alemã não era uma característica exclusiva dos meios intelectuais argentinos. A rigor, essa tradição possuía tanta ascendência e prestígio nos países centrais quanto em alguns países da América Latina e estava no centro da atenção internacional de todos aqueles que, na época, estavam em busca dos fundamentos epistemológicos que pudessem conferir à disciplina sociológica respeitabilidade no conjunto das ciências sociais. Como é bem sabido, em meados da década de 20, o sociólogo norte-americano Talcott Parsons dirigiu-se à Alemanha uma viagem, por outro lado, que dava continuidade ao padrão de seus predecessores imediatos que se dirigiram para lá em busca da ciência social - e na volta publicou parte de sua tese de Doutorado referente à interpretação do capitalismo em dois autores alemães, Werner Sombart e Max Weber (Parsons, 1928; 1929). Mais tarde, em 1937, publicava La Estructura de la Acción Social, uma obra que, de alguma maneira, mudaria o curso da sociologia e que não pode ser explicada a não ser a partir de seu encontro com a cultura sociológica alemã, especialmente com a figura de Max Weber (Parsons, 1970). Da França, Raymond Aron seguiu um itinerário similar e escreveu, ao retornar, a pedido expresso de Celestin Bouglé, o informe mais abrangente e talvez, na ocasião, mais consultado sobre a sociologia na Alemanha, $L a$ Sociología Alemana Contemporánea (1953). Como é sabido, tanto Parsons como Aron liderariam, aind a que com conseqüências desiguais, a introdução da sociologia alemã em seus respectivos países (Shils, 1970; Hirschhorn, 1988). Também na América Latina a sociologia alemã provocaria forte ressonância, especialmente no México e no Brasil. No México, o grupo editorial do Fondo de Cultura Económica e a Revista Mexicana de Sociología, estimulados por um grupo de exilados espanhóis, atuariam como os principais focos de difusão (Arguedas e Loyo, 1979; Reyna, 1979, Zabludovsky, 2002). No Brasil, essa difusão foi canalizada pela revista Sociologia, fundada em 1939 por Emílio Willems (Villas Boas, 1994).

Seja como for, tudo revela revolta contra o positivismo e o ingresso editorial da cultura alemã: é então, nesse contexto, que a obra de Max Weber começa a ser objeto de atenção nos meios sociológicos. Contudo, durante os anos 30, a presença de Weber no conjunto dos autores alemães é ainda relativamente marginal. Simmel, Vierkandt e Von Wiese atraem as preferências. O índ ice onomástico da Historia de la Sociología en Latinoamérica, de Alfred o Poviña, publicada em 1941, de al- 
guma forma reflete esse panorama: o nome de Max Weber tem sete menções contra 32 de Durkheim, 22 de Tarde e 19 de Simmel.

Marginal, também, é a presença de Weber no ca mpo editorial. De fato, ainda que na época - como visto - as edições espanholas de sociólogos alemães se incrementam, a de Max Weber não consta dentre elas. E tem mais, a seção "Proposições para futuras traduções (livros cuja tradução é desejável)", do catálogo Filosofía Aleman a Traducida al Espanol, também não inclui nenhum título de Weber (Schmidt-Koch, 1935). O catálogo sugeria, porém, La Sociología como Ciencia de la Realidad, de Hans Freyer, que mais tarde seria traduzido por Francisco Ayala para sua coleção Biblioteca de Sociologia da editora Losada; Lebensanschauung, de George Simmel; Die drei Nationalökonomien, de Werner Sombart; Einheit der Sinne e Die Stufen des Organischen und der Mensch, de Hemult Plessner; e Comunidad y Sociedad, de Ferdinand Toennies, que seria também editado mais tard e por Ayala na coleção da Losada. Esse dado é, de certo modo, revelador do estado do campo: por volta de meados da década de 30 a sociologia alemã restringe-se, fundamentalmente, aos nomes de Simmel, Toennies, Sombart, Spann, Freyer e Vierkandt, entre outros, e nos põe de sobreaviso perante a corriqueira "ilusão retrospectiva" de atribuir a Weber, dada sua importância contemporânea, u m lugar no passado que, na época, não the cabia.

\section{AS PRIMEIRAS INTERPRETAÇÕES}

No entanto, e como foi ressaltado previamente, já por volta dos anos 40 , Weber começa a ganhar maior notoriedade entre nossos professores de sociologia e sua obra é objeto de uma atenção mais sistemática. Em 1947, Gino Germani, que na ocasião dirigia uma coleção de livros de ciências sociais, Ciência e Sociedade, na editora Abril, anunciava o próximo lançamento da La Sociología Alemana Contemporánea, de Raymond Aron, nos seguintes termos:além de um estudo sobre os sociólogos alem ães - dizia - "[o livro de] Aron presta uma atenção especial a Max Weber, dedicando-lhe um extenso capítulo da obra". A declaração revela, então, não somente a importância e reputação da sociologia alemã entre o público de língua espanhola, mas também a importância que havia adquirido Weber na constelação dessa tradição. Por outro lado, nos trabalhos apresentados na Primeira Reunião Nacional de Sociologia, celebrada em Buenos Aires em 1950, as reiteradas referências a Max Weber sugerem que a invocação de seu nome 


\section{Alejandro Blanco}

já era um lugar-comum nos diálogos da comunidade dos sociólogos (Cuevillas, 1950).

Nessa ocasião, como foi antecipado, a sociologia era um campo em formação. De fato, entre 1940 e 1950, a disciplina experimenta um importante processo de institu cionalização. Aparecem as primeiras instituições especializadas nos estudos sociológicos, a primeir a publicação oficial consagrada à matéria, as prim eiras coleções de livros especializadas e as principais organizações formais da disciplina. Em 1940, e sob a direção de Ricard o Levene, foi fundado na Faculdade de Filosofia e Letras da Universidade de Buenos Aires o primeiro Instituto de Sociologia; no ano seguinte, na Universidade Nacional de Tucumán, o Instituto de Pesquisas Econômicas e Sociológicas, dirigido por Renato Treves. Além do mais, surgiram a primeira publicação oficial consagrada à matéria, o Boletín del Instituto de Sociología, que seria editado com regularidade entre 1942 e 1947, as duas primeiras coleções de livros, a Biblioteca de Sociologia, da editora Losada, dirigid a por Francisco Ayala, e a coleção anteriormente mencionada, dirigid a por Gino Germani, que, por essa ocasião, realizava tarefas de pesquisa no Instituto de Sociologia de Ricardo Levene (Blanco, 2003). Por sua vez, em 1947 apareceu o prim eiro tratado relativo ao tema, o Tratado de Sociología, redigido pelo próprio Ayala e editado pela mesma editora em três grossos e maciços volumes. Finalmente, em 1950 são criadas as princip ais organizações formais da disciplina: a Academia Argentina de Sociologia, dirigida por Alberto Baldrich, e a Associação Latino-Americana de Sociologia, presidida por Alfredo Poviña.

No entanto, essa implantação institucional relativamente bem-sucedida não foi resultado de uma unidade intelectual prévia. Pelo contrário, em termos intelectuais, a sociologia encontrava-se fragmentada: era objeto de diversas representações e estava associada com diferentes atividades intelectuais. No seu interior cabia o estudo histórico das idéias sociais, o estudo dos sentimentos e crenças que formam o caráter de uma nação, o exame do presente por meio de sua morfologia, como o estudo das doutrinas sociológicas. A própria produção intelectual refletiu essa heterogeneidade. Ainda que o livro de texto ou o tratado chegassem a representar o gênero mais comum, os sociólogos da época praticavam igualmente o ensaio político, a história das idéias e os informes de pesquisa empírica. 
Dessa forma, e dado seu caráter de disciplina em formação, uma parte dessa produção intelectual esteve destinada a estabelecer suas credenciais e obter reconhecimento no campo mediante uma definição de seu domínio temático e sua especificidade metodológica. O debate relativo a este tópico se apresentou nos seguintes termos: era a sociologia uma ciência do espírito ou uma ciência positiva? devia orientar-se pelo método da compreensão ou por métodos naturalistas? Foi no contexto desse campo temático que a obra de Max Weber despertou o interesse dos sociólogos locais, o que explica que o eixo dessa recepção se tenha centrado quase exclusivamente nas questões relativas ao método. De modo geral, duas questões atraíram a atenção dos comentaristas: o método da compreensão e o conceito do tipo id eal.

$\mathrm{Na}$ interpretação de Raúl Orgaz, a obra de Weber resultava relevante no que se refere a dois problemas diferentes mas estreitamente relacionados: o da definição da realidade do social e o do método. Quanto ao primeiro problema, Orgaz situava a "sociologia compreensiva" de Weber na linha da sociologia formalista de Simmel e Von Wiese. Su a definição da realidade do social como atuação humana dotada de sentido permitia assim, segundo nosso intérprete, contrapô-la tanto a u ma "concepção romântica" da sociedade, que vê nela uma entidade vivente ou uma personalidade, quanto a uma "concepção mecanicista", que priva a ação humana de sentido subjetivo.

No que diz respeito à questão do método, Orgaz - que seguia nesse ponto a interpretação de Pitirim Sorokin, na época a mais au torizada, ao menos entre o público de língua espanhola (Sorokin, 1928) - argumentava que o mérito da metodologia sociológica de Weber residia em haver substituíd o as noções de causa e efeito, próprias de uma definição mecanicista da ação humana, pelas de "variável" e "função". Os estudos religiosos de Weber, segundo nosso intérprete, ilustravam essa aproximação metódica, caracterizada por uma rejeição às interpretações unilaterais (reducionismo econômico e filosofia econômica da história) em proveito de um esquema funcional e interd ependente. A esse respeito, apontava: "O pluralismo causal toma o lugar do ilu sório monismo; a relação funcional substitu i a relação unilateral; a variável ocupa o lugar da causa, e a função o do efeito; a interdependência funcional, por sua vez, substitui a dependência singular" (Orgaz, 1950:163). 


\section{Alejandro Blanco}

Em um argumento muito similar ao que poucos anos mais tarde Talcott Parsons utilizaria, Orgaz reconhecia que tanto em Weber como em Durkheim e Pareto era possível encontrar uma proposição nova e convergente sobre o problema da causalidade, "verdadeiro coração de uma sociologia científica" (idem:58). E tem mais. Orgaz reconhecia que o mérito tanto de Weber como de Durkheim residia em que ambos haviam tirado a indagação sociológica "do atraente mas arriscado caminho da introspecção e da intuição, domínios favoritos de ou tros sociólogos, como Tard e e Simmel" (ibidem). Nesse sentido, Orgaz argumentava que ainda que Weber reconhecesse a compreensão como o método característico das ciências sociais, tratava-se de um reconhecimento carente de implicações filosóficas, e que buscava, pelo contrário, "integrar esse método, que permite captar por intuição um sentido, com a explicação estritamente científica” (idem:149).

A apresentação do sociólogo alemão realizada por Alfredo Poviña começava com uma classificação retrospectivamente curiosa: arrolava La Ética Protestante y el Espíritu del Capitalismocomo parte de seus "trabalhos econômicos" e ao mesmo tempo atribuía à Economía y Sociedad o status de verdadeiro trabalho sociológico. Ao contrário de Orgaz, Poviña identificou Weber como "o melhor representante da sociologia histórico-cultural ou espiritualista" (Poviña, 1941a:5). Essa identificação aparece en fatizada em outra passagem do texto em que, ao se referir à famosa máxima weberiana segundo a qual a sociologia é uma ciência que pretende entend er, interpretando, a ação social, para dessa maneira explicá-la causalmente em seu desenvolvimento e efeitos, Poviña comenta: "[a sociologia] é uma disciplina de compreensão interior, em primeiro lu gar [e que] [d]essas noções se deduz que esta ciência pretende, antes de tudo, compreender, e só secundariamente, explicar a ação social" (idem:7). Nas conclusões de seu ensaio, Poviña comentava:

\footnotetext{
“[...] parece que sua doutrina, ainda que não rigorosam ente metódica nem orgânica, representa a melhor expressão da sociologia como ciência de tipo cultural ou espiritualista. Só considera a matéria da vida social com o reação exagerada contra o formalismo, vazio de conteúdo, da corrente iniciada por Simmel" (idem:14).
}

Finalmente, Poviña, que também seguia Sorokin, repetia as mesmas críticas deste - críticas que Orgaz, curiosamente, havia omitido - segundo as quais, a fragilidade da obra de Weber residia em terminar 
sacrificando o ponto de vista funcional a favor de um causalista, no caráter confuso de sua noção de ética e no fato de que os "acontecimentos", no que se refere à origem do capitalismo, contradiziam sua teoria - apesar do que concluía seu ensaio, confessando que a obra de Weber oferecia "a sistematização de maior prestígio intelectual na sociologia alemã dos últimos tempos" (idem:15).

Em Sociología y Filosofía Social, Renato Treves fez uma interpretação muito afinad a com a que, na ocasião, Raymond Aron havia elaborado na França. Treves reconhecia que, no contexto da disciplina, a perspectiva de Weber representava uma "posição particu lar", que não se ajustava "às direções examinadas ao longo do livro (positivista, formalismo crítico e empírico, fenomenologia e idealismo e historicismo)". Treves acrescentava, também, que "sua obra, talvez por ser irredutível a direções e a sistemas fixos, pode proporcionar as mais profundas e conclusivas contribuições para compreender a natureza do método e do objeto da sociologia" (Treves, 1941:116). De acord o com o argumento de Treves, o mérito de Weber consistia em ter conseguido definir a sociologia como uma disciplina não pertencente nem às ciências naturais nem às ciências históricas e em ter ressaltado que o método da compreensão, enfatizado por Dilthey, deveria ser integrado em uma explicação cau sal, fundado no critério da adequação e da probabilidade, e diferente nesse sentido tanto da causalidade geral das ciências da natureza como da cau salidade individual das ciências históricas. Finalmente, Treves destacava como meritório da posição metodológica de Weber o fato de ter revelado o caráter limitado e relativo da objetividade, ao reconhecer que esta não pode ser fundada em valores culturais universais mas naqueles valores que, em uma determinada época, se tornam dominantes.

Finalmente, a interpretação de Francisco Ayala esteve praticamente centrada em um exame da construção e das aplicações do tipo ideal e em sua importância para o conhecimento sociológico. Ayala, que naquela ocasião havia traduzido e editado La Sociología, Ciencia de la Realidad: Fundamentación Lógica del Sistema de la Sociología, de Hans Freyer, ofereceu uma interpretação do tipo ideal weberiano seguindo a linha interpretativa deste, ressaltando especialmente sua orientação em direção à captação da peculiaridade do objeto histórico. Nesse sentido, apresentou uma caracterização da metodologia do tipo ideal como um tipo de aproximação intermediária entre a sociologia formalista e uma sociologia histórica. A esse respeito, apesar de ter ob- 


\section{Alejandro Blanco}

servado criticamente a tendência formalista da conceitu ação weberiana que costuma recair "no tipo de conhecimento físico-matemático", concluiu, não obstante, afirmando o seguinte:

\footnotetext{
"O mérito imperecível de Weber - salientava - consiste em ter sabido dar conteúdo histórico e contexto histórico à conceituação sociológica, sem os quais o objeto da sociologia se perde em uma série de formas, ao mesmo tempo que acentuava, perante a história, o formalismo dos conceitos sociológicos, destinados a servir ao conhecimento de estruturas que se repetem com conteúdos históricos variáveis" (Ayala, 1947:124).
}

Como visto acima, as visões de Weber entre nossos professores de sociologia eram bastante divergentes. Levene, talvez o menos familiarizado com a obra do sociólogo alemão e mais atento, por outro lado, à Escola de Durkheim, incluiu Weber, junto com Karl Marx, na família das "concepções unitárias" das quais era necessário tomar distância, qualificando-as de "ideológica" e de "econômica", respectivamente (Levene, 1942) ${ }^{4}$. Na interpretação de Poviña, Weber aparecia como um dos expoentes de uma concepção da ciência sociológica como ciência cultural ou espiritualista, ao mesmo tempo que Renato Treves procurava diferenciar Weber das distintas orientações que na época dominavam a disciplina, situando-o em todo caso em uma posição distanciada tanto de uma representação da sociologia como ciência cultural quanto de uma concepção naturalista da mesma. De qualquer modo, o certo é que em torno da figura de Weber e, em especial, de sua perspectiva metodológica, já existia certa tradição interpretativa e algumas opiniões divergentes.

\section{RENOVAÇÃO DA DISCIPLINA E NOVAS CHAVES INTERPRETATIVAS}

Em 1940, na inauguração das atividades do Instituto de Sociologia da Faculdade de Filosofia e Letras da Universidade de Buenos Aires, seu diretor, Ricardo Levene (1942:7), anunciava com certa satisfação que "a crise filosófica que acometeu esta disciplina de conteúdo complexo" havia felizmente terminado. Isso significava para Levene a existência de um relativo acordo sobre o objeto, as tarefas e o método da disciplina emergente. No entanto - e como será visto mais adiante -, esse acordo era mais uma declaração de intenções que uma constatação. 
Por volta dos anos 40, de fato, teve início um movimento de renovação radical dos ideais intelectuais da disciplina na América Latina. Tratou-se de um movimento tendente a fazer da sociologia uma ciência empírica. Nos círculos de língua espanhola, o primeiro livro, de grande circulação e decisivo a este respeito, foi Sociología: Teoría y Técnica, de José Medina Echavarría, lançado em 1941, que Gino Germani celebraria mais tarde como aquele que iniciou "a difusão da sociologia científica na América Latina". No prólogo à primeira edição, Medina Echavarría escrevia:

\begin{abstract}
"A questão é que não pode existir uma ciência sociológica sem uma teoria e sem uma técnica de pesquisa. Sem uma teoria, quer dizer, sem um conjunto de categorias depurado e um esquema unificador, o que se conhece [atualmente] como sociologia não só não será ciência, como tam bém carecerá de sentid o para a pesquisa concreta e para a resolução dos problemas sociais do dia-a-dia. Sem uma técnica de pesquisa definida, ou seja, submetida a padrões rigorosos, a pesquisa social não apenas é infecunda, mas incita à ação, sempre disposta, dos charlatães e dos audaciosos. [...] A Sociologia tem sempre sido a mais castigada pelo improviso, e esse deve ser arrancado pela raiz dos meios juvenis." (1941:8)
\end{abstract}

A proposta de Medina Echavarría de transformar a sociologia em uma ciência significava, por sua vez, a aplicação do "método científico" ao estudo das questões humanas e a superação da dicotomia ciências naturais/ ciências sociais. Ainda quando reconhecia a diferença entre a matéria de umas e outras, advertia que o método científico é o mesmo para todas as ciências. Esse programa de unificação das ciências, ou melhor, de uma "unid ade do método científico" será o componente mais decisivo da reorientação sugerida por esse autor.

Em sintonia com as formulações de Karl Mannheim, Medina Echavarría enfatizava a função instrumental da sociologia, que deveria servir de guia orientador para a ação humana. Aos seus olhos, a redefinição da sociologia pedia a rejeição de dois redu cionismos que haviam dominado, até o momento, a discu ssão sociológica no referente ao objeto da disciplina. Por um lado, o "red u cion ismo naturalista" (tanto em sua variante organicista quanto na ambientalista) que concebe os acontecimentos sociais como fenômenos naturais e, portanto, precisa analisá-los com os instrumentos das ciências naturais. Por outro, o "redu cionismo culturalista" (em suas versões historicistas ou feno- 


\section{Alejandro Blanco}

menológicas) que concebe acontecimento social como uma manifestação da cultura ou do espírito e que privilegia, por conseguinte, métodos especiais de apreensão dessas totalidades de sentido. Perante esses dois tipos de reducionismo, Medina Echavarría declarava que "a sociologia é uma ciência positiva, ou seja, em pírica e indutiva". Em consequiência, podiam ser aplicados a ela métodos que haviam demonstrado sua fertilidade em outras ciências: observação, experimentação e comparação. O fato de a sociologia lidar com dados sociais, de caráter eminentemente histórico, não deveria modificar em nada, segundo o autor, a essência da proposta. Nesse sentido, Medina Echavarría apelava para o caso da "sociologia norte-americana" como exemplo bem-sucedido dessa nova atualização, em um extenso capítu lo intitulado precisamente "A Pesquisa Social e suas Técnicas". A esse respeito, o autor havia afirmado que "é evidente que o centro da produção sociológica em língua inglesa se encontra, neste século, nos Estados Unidos, onde a Sociologia alcança um desenvolvimento extraordinário e tem uma significação positiva na cultura e na educação" (Medina Echavarría, 1940:205). Essa alusão precoce à experiência norte-americana resulta bastante significativa dentro de um contexto em que a sociologia alemã constituía o universo quase exclusivo de referência entre os praticantes d a disciplina. Poucos anos depois, a referência à sociologia norte-americana, que começará a desbancar a alemã, haveria de se converter em um dispositivo central de legitimação da disciplina (Blanco, 2004).

Uma nova interpretação da metodologia sociológica de Max Weber deverá constituir um capítulo decisivo dessa reorientação preconizada por Medina Echavarría. De fato, o autor insistirá repetidas vezes na necessidade de afastar Weber das "posições culturalistas" que, partindo da dicotomia entre ciências do espírito e ciências da natureza, reduziam o dado social a um dado do espírito, concebido como "essência" ou como "conexões ou totalidades de sentido" e, dessa maneira, negavam a razão de ser da sociologia. Ou, em todo caso, essa última deixava de ser "uma pesquisa da realidade empírica para transformar-se em uma disciplina filosófica e especulativa" (Medina Echavarría, 1941:52). Echavarría identificava no historicismo, no neo-hegelianismo e na fenomenologia, "[que] influenciaram de maneira decisiva grande parte da sociologia alemã das três primeiras décadas do século XX", esse "lamentável culturalismo" (idem:46 e 53), uma companhia da qual era necessário separar Max Weber. Pouco de-

\section{2}


pois, no prefácio da edição espanhola de Economía y Sociedad, Med ina Ech avarría advertia que "o que chegou ao público de sua obra e que se repete nas salas de aula não deixa de ser uma deformação ou caricatura de seu próprio pensamento" (Medina Echavarría, 1992:XIX). Em um gesto que demonstra bem a direção das apostas, ele enfatizava a interpretação de Talcott Parsons, a quem não hesitava em qualificar como "um dos melhores conhecedores atuais de Max Weber", publicada poucos anos antes em La Estructura de la Acción Social (idem:XXII).

$\mathrm{Na}$ Argentina, os primeiros sinais de uma renovação nessa direção começaram a se notar na exp eriência relacionada com o Instituto de Sociologia de Buenos Aires e com o Instituto de Pesquisas Econômicas e Sociológicas de Tucumán, especialmente em torno de três figuras da sociologia local, Renato Treves, Miguel Figueroa Román e Gino Germani. De fato, ambas as instituições foram ponto de partida das primeiras pesqu isas empíricas desenvolvidas dentro das universidades e abrigaram as primeiras demandas a favor de uma incorporação $d a$ pesquisa social às tarefas da sociologia: no Instituto de Buenos Aires, Germani levou a cabo uma pesquisa sobre as classes médias e participou ativamente, durante um tempo, como representante do Instituto na Comissão Assessora para a realização do IV Censo Nacional (Blanco, 2003); o In stituto da Universidade de Tucumán promoveu um programa de pesquisas empíricas sobre a classe operária em Tu cumán;e Treves empreendeu uma pesquisa sobre os cortiços, publicad a como apêndice de um livro intitu lado Introducción a las Investigaciones Sociales (Treves, 1942), e Miguel Figueroa Román, um estreito colaborador de Treves, que mais tarde ocuparia seu lugar na direção do Institu to, havia iniciado uma série de pesquisas na mesma direção.

Aqui também a renovação da disciplina esteve estreitamente associada a esse dup lo movimento presente em Medina Echavarría: por um lado, o de fazer da sociologia uma ciência empírica e aplicada e, por outro, a referência à sociologia norte-am ericana como uma experiência exemplar nessa direção. Assim, em Introducción a las Investigaciones Sociales, lançado em 1942, Renato Treves reconhecia qu e, apesar da importância que havia adquirido o ensino da sociologia na América Latina durante os últimos anos, "uma certa desorientação sobre seus próprios problemas e objetos assim como uma tendência a um perigoso enciclopedismo" eram, ainda, os aspectos mais visíveis do estado da disciplina. Treves indicava, também, que "no referente às 


\section{Alejandro Blanco}

pesquisas sociais e sociográficas é fácil comprovar que na América Latina não se encontram pesquisas comparáveis às realizadas, por exemplo, em Pittsburgh, não somente pela quantidad e de dados e observações recolhidas, mas também pela organização técnica e o espí-

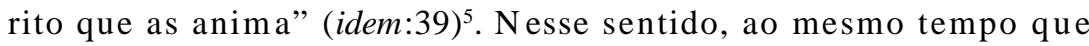
instava a estabelecer uma relação mais estreita entre ensino da teoria e pesquisa prática dos problemas regionais, apontava, também, para a necessidade de observar "a experiência americana" com o fim de encontrar pontos de apoio para a criação e organização de institutos universitários de pesquisa, como modo de neu tralizar a tendência ao enciclopedismo.

Opiniões na mesma direção - e ainda mais enfáticas - eram expostas por seu colaborador, Miguel Figueroa Román, no prefácio de Sociografía y Planificación, lançado em 1946, no qual afirmava:

"A ciência oficial ainda não outorgou, entre nós, a carta de cidadania à planificação nem à sociografia. N as universidades não se ensina a mo derna técnica da organização estatal nem se procu ra u m conhecimento integral da realidade social. Os institutos de pesquisa só acidentalmente se ocupam dos problemas sociais e em nenhum caso sistematizam a aquisição dos conhecimentos necessários para seu estudo" (Figueroa Román, 1946:11).

Sobre essa falta de informação referente ao desenvolvimento da pesquisa empírica ou sociográfica, Figueroa Román declarava: "Como é possível que nossos sociólogos não tenham dado a relevância merecida a uma orientação da ciência que ocupa milhares de volumes nos Estados Unidos?" (idem:196-197). E atribuía essa situação à orientação que predominava no ensino universitário, formada, segundo ele, "sobre velhos moldes europeus, de sentido preferentemente humanístico, e de escasso valor prático". Ao contrário do que ocorre nos Estados Unidos - continuava -, nas universidades argentinas "en sina-se só sociologia teórica, história da ciência e evolução do pensamento sociológico, o que sem dúvida serve para dar relevân cia ao espírito, mas que deve levar o complemento ind ispensável da sociologia aplicada, com seus métodos de pesquisa e sua vinculação à realidade social" (idem:197).

Nessa mesma época, Germani publicou um ensaio referente às relações entre sociologia e planificação, expondo argumentos similares aos utilizados por Medina Echavarría. "A sociologia-afirmava-não

\section{4}


pode deixar de ser uma ciência empírica e indutiva se é que verdadeiramente pretende cumprir sua função orientadora em uma sociedade que se encaminha em direção à planificação" (Germani, 1946a). Traduzida para os termos de uma disputa pelo método, a própria possibilidade dessa função orientadora implicava, então, a conversão da sociologia em uma ciência positiva (empírica e indutiva) e o conseqüente abandono do método da intuição e/ ou de outras formas alternativas perante a observação controlada, pois só deste modo a sociologia estaria em condições de descobrir uniformidades da ação humana cujo conhecimento pudesse contribuir para a elaboração de estratégias de planificação. Converter a sociologia em u ma ciência positiva implicava, então, desviar o rumo "especu lativo" da reflexão sociológica e desenvolver um programa de pesquisas empíricas sobre aqueles temas que fossem estratégicos para a planificação social (Blanco, 1998). Como se pode notar, as demandas de Treves, de Figueroa Román e também as de Germani aspiravam não somente a atribuir status universitário à pesquisa social, mas também a introduzir mudanças substanciais nos modos de ensino da disciplina.

Todos esses sinais de renovação atingiriam a forma de um argumento sistemático em uma monografia que Gino Germani preparou para o concurso de professor-assistente da Cátedra de Sociologia da Faculdade de Ciências Econômicas da Universidade de Buenos Aires. O texto, que permaneceu praticamente ignorado na literatura relativa à história da sociologia na Argentina, intitulava-se Teoría e Investigación en la Sociología Empírica e estava dedicado a examinar "a possibilidade de u ma ciên cia empírica da realidade social" (Germani, 1946b:3) O texto reunia as diferentes demand as que aquie ali haviam sido identificadas como parte de uma renovação intelectual da disciplina, fundamentalmente a de inclu ir a pesquisa social e suas técnicas nas tarefas da sociologia, e ressaltava, ao mesmo tempo, a relevância da teoria na pesquisa social.

$\mathrm{O}$ argumento central da monografia procurava demonstrar que a separação entre sociografia e sociologia, que naquela ocasião dominava a autocompreensão da disciplina, terminava em uma falsa alternativa:um "empirismo desordenado" ou a "especulação desenfreada". A rigor, essa separação estava baseada em uma interpretação errada tanto da teoria quanto da pesquisa. De fato, a teoria - argumentava Germani - não é uma expressão da realidade nem sua reprodução conceitual, e sim uma abstração efetuada na base de um determinado 


\section{Alejandro Blanco}

interesse cognitivo. Sob esse ponto de vista, nem a teoria nem os conceitos que a compõem são capazes de captar a realidade em toda sua plenitude. Ao mesmo tempo, en fatizava, não há conhecimento sem teoria. Nesse sentido, a própria noção de "acontecimento" pressupõe a presença do elemento lógico. Era, portanto, infrutífero delegar à sociografia a tarefa "descritiva" de recolher os acontecimentos, pois eles se constituem, precisamente, em função de um esquema conceitual que guia sua observação. Em suma, teoria e pesquisa não podiam ser vistas separadamente, e sim mutuamente relacionadas.

Dessa forma, Germani ressaltava a necessidade de inclinar-se à formulação de um esquema analítico unificado capaz de integrar as diferentes perspectivas teóricas vigentes na época. A desordem conceitual patente no espetáculo das teorias em conflito, das intermináveis disputas de diferentes correntes, da pluralidade de pontos de vista e da multiplicação de conceitos era - conforme se acreditava - mais aparente que real. Olhando bem, argumentava, podia se descobrir u ma incipiente, porém firme, unificação da teoria sociológica na direção que havia tomado a sociologia norte-americana nas obras de R. M. Mac Iver, W. Thomas, F. Znaniecki, E. Faris, C. Ellw ood, H. Blum er e T. Parsons, entre outros, nas quais era possível observar tanto uma crítica às tendências mais objetivistas do behaviorismo norte-americano quanto uma demanda pela integração do elemento subjetivo na compreensão da ação humana. Sobre este último aspecto, a grande vantagem dessa tradição, segundo Germani, residia no fato de que, ao contrário das trad ições idealistas alemãs, a in corporação desse elemento subjetivo não pressupunha a negação do caráter empírico da sociologia.

É então no contexto dessa discussão que se deve compreend er sua intervenção em torno de Weber. Sua posição consistiu basicamente em afastá-lo das interpretações espiritualistas ou culturalistas vigentes naquela ocasião. Certamente, na disputa pelo significado da perspectiva weberiana, Germani fez algo mais que disputar uma determinada imagem d a mesma. Na realidade, sua intervenção esteve caracterizada por um exame crítico tanto da sociologia alemã, de enorme gravitação entre nossos sociólogos, quanto de seu impacto - qu e ele avaliava como negativo - na representação da disciplina, de suas tarefas e de seus métodos. As críticas estiveram especialmente dirigidas contra a perspectiva fenomenológica de Alfred Vierkandt, mas também contra as tentativas de Ferdinand Toennies e Hans Freyer de estabele- 
cer uma distinção entre sociologia geral e sociografia. A seu critério, tanto uma como as outras conduziam a uma concepção da sociologia como disciplina de natureza filosófica e não empírica. Nesse sentido, grande parte da tradição alemã carecia de meios para superar aquela dicotomia e alcançar assim uma unificação da teoria e da pesquisa empírica. As palavras finais de sua apreciação sobre essa tradição são bastante eloqüentes:

\begin{abstract}
“[...] pode se afirmar agora - dizia - que a possibilidade de síntese, de visão total, de unificação, cu ja necessidade é tão evidente diante da incoerência e do estado fragmentário em que se arrisca a cair a pesquisa social se carecer de uma teoria unitária, não pode ser procurada na direção que indica a tradição idealista alemã a não ser através da sim ples renúncia ao conhecimento científico - no sentido positivo - da realidade social" (idem:17).
\end{abstract}

Nesse panorama, as únicas exceções eram Max Weber, sobre o qual explanarei logo adiante, e a posição - que Germani citava com aprovação - adotada pelo sociólogo alemão Leopold von Wiese, que, descartando a separação entre sociologia e sociografia, mostrava-se partidário de fazer da sociologia uma ciência empírica.

Naturalmente, a intervenção de Germani privilegiou aquelas questões sobre as quais já existia uma certa trad ição interpretativa, o método da compreensão e o tipo ideal, e incluiu-se no contex to mais amp lo do debate - sintetizado nas páginas anteriores - relativo ao status da sociologia como disciplina e de sua aposta em conferir um lugar de honra à pesquisa empírica na definição de suas tarefas. No contexto desse debate, como vimos, a posição da metodologia weberiana era ambígua. Apesar de ser reconhecida por alguns como parte de uma tentativa voltada para sintetizar as vertentes "naturalista" e culturalista”, conforme a classificação vigente na época, em geral era incluída entre as trad ições espiritualistas alem ãs. A intervenção de Germani consistirá nesse ponto em retirar Weber desse contexto interpretativo (o da dicotomia ciências naturais/ ciências do espírito) e colocar sua aposta metodológica no contexto de uma definição geral e única do proceder científico.

Esta operação interpretativa já havia sido iniciad a por Germani em Teoría e Investigación en la Sociología Empírica. Neste ensaio, de fato, Germani alegava que a dicotomia ciências da natureza/ ciências do espírito, que "havia chegado a ter difusão e a enraizar-se na América 


\section{Alejandro Blanco}

hispânica, especialmente nos círculos filosóficos", havia sido "superada em grande parte na própria Alemanha por obra de Max Weber" (idem:6). Argumentava igualmente que "o conhecimento atua sempre abstraindo e - como mostrou M. Weber em relação às tend ências 'particu laristas' - não há nisso nenhuma diferença entre os fenômenos naturais e os sociais" (idem:23). Segundo Germani, Weber havia mostrado claramente que os "acontecimentos", quer sejam parte da experiência comum ou da elaboração científica, jamais são uma reprodução da realidade, mas sim uma seleção de certos aspectos, princípio que se aplica tanto à realidade natural quanto à histórico-social. Em ambos os casos estamos - dizia Germani - diante de uma infinita e complexa variedade de fenômenos impossível de ser captada plenamente por algum conceito. De todo modo, concluía, a diferença entre ciências naturais e ciências do espírito não radicava no uso de conceitos gerais - uso que na realidade ambas compartilhavam -, mas sim no direcionamento do interesse científico, para o geral, nas primeiras, e para o individual, nas segundas.

Certamente, o próprio projeto de uma definição geral e única do proceder científico ou de uma "ciência unificada", ao qual apontava essa renovação da disciplina, não pode ser compreendido senão no contexto de uma corrente filosófica, o neopositivismo, que dos anos 30 em diante se converteria na fonte de inspiração de todos aqueles que procuravam transformar a sociologia em uma "ciência" (Toulmin, 1974). Na Argentina, o ideário neopositivista foi introduzido em uma época relativamente precoce. Nos anos 40 apareceu Minerva. Revista Contin ental de Filosofía, u ma publicação dirigida pelo filósofo Mario Bunge, que começou a difundir as idéias do neopositivismo associado ao Círculo de Viena. Apesar de não formalm ente integrado à revista, Germani estava ligado a seu círculo e inclusive havia prometido escrever um ensaio consagrado à sociologia norte-americana que, por razões que desconhecemos, não foi publicado ${ }^{6}$. Seu contato com as idéias do neopositivismo relaciona-se a diferentes focos de inspiração. Em primeiro lugar, a uma figura relativamente conhecida, na época, nos círculos de língua espanhola: a do filósofo da ciência Hans Reichembach, membro proeminente do Círculo de Viena, fundador da Escola do Positivismo Lógico em Berlim e autor de La Filosofía Científica, um dos manifestos do novo movimento filosófico ${ }^{7}$. Germani conhecia igualmente a obra de Otto Neurath, Foundation of the Social Sciences, lançad a nos Estados Unidos em 1944, e a Encyclopaedia of 
Unified Science de O. Neurath, N. Bohr, J. Dewey et alii, editada também nos Estados Unidos em 1940. O segund o foco alude a Felix Ka ufman, que, apesar de não estar estritamente ligado à escola do positivismo lógico, compartilhava, porém, algumas de suas premissas, em especial, a relativa à necessidade de uma unificação das ciências. Su a principal obra, Methodology of Social Sciences, ed itada em 1946 por Medina Echavarría no Fondo de Cultura Económica, seria citada por Germani precisamente no referente a esse ponto. Germani encontraria uma fonte adicional de inspiração na tradição "cientista" norte-americana ${ }^{8}$, que, ainda que $\log$ o se revelasse em sintonia com as idéias de Viena, havia se originado nas tradições americanas do pragmatismo, do behaviorismo e do operacionalismo (Platt, 1996). Sua figura mais influente foi, sem dúvida, George Lundberg, reconhecido durante os anos 40 e 50 como um dos principais porta-vozes da introdução da "ciência" na sociologia e autor de dois livros de textos sobre o método científico amplamente lidos e utilizados, Social Research (1929) - resenhado pelo próprio Germani por volta da metade dos anos 40 no Boletín del Instituto de Sociología e ditado em 1949 pelo Fondo de Cultura Económica - e Foundations of Sociology (1939), uma espécie de manifesto metassociológico em que Lundberg estabelecia os passos daquilo que considerava como método científico: produção de hipótese, observação e coleta d e dados, classificação e organização dos dados colhidos e generalização de uma lei científica aplicável a todos os fenômenos similares do universo analisado sob determinadas condições específicas. Entre 1940 e 1945, Lundberg dirigiu Sociometry, uma publicação que Germani acompanhava de perto (o Instituto de Sociologia de Buenos Aires recebia periodicamente essa publicação) e a cujas pesquisas dedicaria, anos mais tarde, um ensaio elogioso incluído em La Sociología Científica (Germani, 1956)

Certamente, não é que Germani aderisse totalmente aos diferentes argumentos expostos por cada uma dessas tradições. Sua relação com as idéias do neopositivismo esteve caracterizada mais pelo ecletismo do que pela intenção de elaborar uma nova ortodoxia. Inclu sive, ele havia expressado uma série de reservas em relação a certas derivações do programa neopositivista em sua pretensão de atingir um "racionalismo sem resíduos" ${ }^{9}$. Se acudia a todas elas, no entanto, era porque reconhecia ali um movimento intelectual alimentado por uma idéia de ciência que se mostrava afim com sua estratégia de fazer da pesquisa empírica o locus da sociologia. Dessas diferentes tradições, 


\section{Alejandro Blanco}

Germani adotou três idéias fundamentais das quais se valerá em sua polêmica relativa a método: a) a primazia conferida à pesquisa empírica na produção de conhecimentos; b) a idéia de que as principais bases do conhecimento residem na verificação experimental de caráter público, intersubjetivo, e não na experiência pessoal; c) a convicção de que não existe diferença entre ciências naturais e ciências sociais ou da cultura no que se refere a seus fundamentos lógicos. Em todo caso, é no contexto desse panorama de referência neopositivista que - como veremos adiante - se torna compreensível tanto sua interpretação da metodologia weberiana em tom cientificista quanto a anacrônica atribuição a Weber de um vocabulário que, como no caso da verificabilidade de uma proposição, não estava disponível na época.

Em dois trabalhos apresentados por ocasião do Primeiro Congresso Latino-Americano de Sociologia celebrado em Buenos Aires em 1951, Germani retomou o tema com a seguinte declaração: “apesar de pertencer à tradição idealista alemã - afirmava - [Weber] chegou a formular uma metodologia que reduziu consideravelmente a brecha entre as ciências naturais e as culturais" (Germani, 1952a:111). Sua argumentação articulou-se da seguinte maneira: em primeiro lugar, Germani procurou relacionar o método da compreensão com a explicação, contrapondo-se ao lugar secundário reservado a esta última, entre outros, por Poviña. Era precisamente essa separação entre compreensão e explicação uma das críticas que Germani dirigia aos intérpretes latino-americanos d e Weber. Ao se referir às dificu ldades para superar o dualismo entre sociologia, entendida como disciplina cultural ou filosófica, e pesquisa empírica, afirmava:

“[...] muitos sociólogos latino-americanos pensam que essa dificuldade deixa de existir quando se adota uma metodologia inspirada em Max Weber, baseada na utilização do 'tipo ideal' e do recurso atual à compreensão e à explicação. No entanto, sua tentativa não pode ser completamente satisfatória, pois ao considerar que o momento da ‘compreensão' corresponde aos aspectos 'espirituais' do social, e o da 'explicação', aos naturais, volta a introduzir um dualismo ontológico que conduz, u ma vez mais, ao divórcio entre teoria e pesquisa" (Germani, 1952b:88).

Em segundo lugar, tentou dissociar o método da compreensão de qualquer procedimento puramente intuitivo, argumentando que o 
próprio Weber rejeitava o intuicionismo por razões éticas, pois - dizia - "pode facilmente se transformar em um incentivo para evadir ou negligenciar o penoso processo da verificação [...] cu ja característica essencial é seu alcance intersubjetivo" (Germani, 1952a:112). Assim, ainda que a compreensão incluísse a observação de fenômenos imateriais, como os motivos das ações, estes últimos devem manifestar-se por meio de uma expressão simbólica qualquer, permitindo, desse modo, sua captação por in ferência. Em todo caso, o que Germani pretendia desautorizar era a associação da compreensão a um procedimento destinado a captar alguma essência ou fenômeno irredutível a sua expressão em um conjunto de proposições empiricamente verificáveis.

No que se refere ao tipo ideal como método de compreensão de conexões objetivas de sentido, Germani afirmava que, "apesar das interpretações habitualmente conferidas, [o tipo ideal] não difere, em sua fundamentação lógica, dos procedimentos empregados nas ciências naturais" (ibidem). O tipo ideal w eberiano, argumentava, é uma construção arbitrária que, se bem possui alguns elementos extraídos da realidade, não pretende reproduzi-la. Pelo contrário, sua construção resulta de uma estilização que se realiza mediante a exacerbação de alguns aspectos extraídos de uma pluralidade de casos concretos. Nesse sentido, aind a que irreal, o tipo id eal oferece a possibilidade de estudar os casos reais que se apresentam, já que, ao estar dotado de coerência lógica, permite estudar o fenômeno em questão em condições simples e claramente definidas, chegando inclusive à possibilidade de formular leis condicionais e tendenciais sobre este. Em termos lógicos, refletia Germani, o mesmo ocorria com as ciências naturais. Então, assim como as regras de um mercado perfeito, a lei da queda dos corpos só se cumpre em um vazio absoluto, isto é, em condições irreais ou ideal-típicas. Dessa maneira, segundo Germani, o emprego do tipo ideal na pesquisa social não implicava, sob nenhum aspecto, um procedimento diferente ao das ciências naturais.

\section{CONCLUSÕES}

Ao longo deste trabalho procurei mostrar que as disputas interpretativas em torno do significado da metodologia weberiana foram reflexo de concep ções diferentes da disciplina e que, nessa medida, só podem ser compreendidas como parte de um debate mais abrangente relativo à definição tanto de suas tarefas quanto de seu método. A di- 


\section{Alejandro Blanco}

fusão de Weber em espanhol ocorreu em um momento de transição, caracterizado pelo aparecimento de uma série de tentativas de renovação dos ideais intelectuais da disciplina que vieram a confluir no projeto de transformar a sociologia em uma ciência empírica e analítica. Um componente importante dessa renovação foi o deslocamento da referência à sociologia alemã para a norte-americana. A nova interpretação de Weber ensaiada por Germani não pode ser dissociada, então, nem desse movimento de renovação nem da aparição desse novo centro de referência que é a sociologia norte-americana. Nesse sentido, a disputa em torno do significado da metodologia sociológica de Max Weber não fez mais que refletir as tensões e linhas de força de um campo, na época, em formação. Nesse contexto, as referências a Weber funcionaram, de algum modo, como motor das transformações intelectuais que o campo experimentava naquela ocasião e que, poucos anos depois, em meados dos anos 50, se cristalizariam na institucionalização de uma fórmula intelectual conhecida por "sociologia científica”.

A imagem de um autor estabelece-se em função dos contextos culturais de interpretação assim como dos projetos e das apostas intelectuais de seus receptores. Os primeiros intérpretes de Weber estavam mais inclinados ao ensino que à pesquisa. $\mathrm{Na}$ época, a sociologia era ensinada como matéria auxiliar de outras disciplinas. Essa posição dos professores de sociologia no sistema universitário somada a suas próprias trajetórias profissionais (a maioria deles era formada em direito ou em filosofia) explicam o tipo de produção intelectual que eram capazes de elaborar, limitada, na sua grande maioria, a um exame - muito tradicional, por outro lado - das idéias sociológicas, em suas duas variantes mais conhecidas, o tratado e o livro de texto. Sua leitura de Weber assumiu assim a forma de "inventário" em uma prática da sociologia mais consagrada ao "comentário" das dou trinas sociológicas que à análise dos fenômenos sociais em si mesmos.

Em um meio habituado a se referir mais ao passado que ao presente, e, mais especificamente, ao passado das idéias, o movimento de renovação pretendeu focalizar a disciplina no presente, no exame da vida contemporânea. A fórmula que unia a sociologia à planificação expressou, naquele momento, esse novo enfoque. Nesse contexto, a interpretação da metodologia weberiana proposta por Germani só pode ser compreendida à luz de suas preocupações em torno da pesquisa empírica em particular e, mais especificamente, das relativas à 
necessidade de integrar teoria e pesquisa social. Sua interpretação de Weber assumiu a forma de uma "integração analítica" que pudesse dotar a pesquisa de um marco de referência unificado, antes que de um inventário. Essa diferença nos projetos intelectuais de uns e outros contribui para explicar os rumos interpretativos que exibiram a propósito da metodologia de Max Weber.

De certo modo, essas diferentes interpretações de Weber vieram expressar não somente duas formas de entender a disciplina, mas também representações diferentes da própria tradição sociológica. $\mathrm{Na}$ época, a disciplina não estava articulada em torno de um esquema conceitual e metodológico unificado. Mais especificamente, existiam duas representações da tradição sociológica, uma empirista e outra pluralista. A primeira delas havia sid o elaborada pela influente "Green Bible" de Park e Burgess, Introduction to the Science of Sociology, d e 1921, que traçava uma história da disciplina sob a forma de um progressivo deslocamento da especulação ao redor dos fenômenos sociais em favor da observação rigorosa dos acontecimentos sociais. A segunda foi elaborada poucos anos depois por Pitirim Sorokin, em Contem porary Sociological Theories. Em contraste com a anterior, Sorokin ind icava que ainda que a primeira tarefa do sociólogo fosse tratar dos acontecimentos antes que das teorias, não era a unidade - reconhecia -, mas sim a diversidade de teorias, muitas delas, inclusive, contraditórias entre si, o que melhor caracterizava o campo.

Os primeiros intérpretes de Weber conservaram uma concepção "pluralista" da tradição sociológica, na mesma linha de Pitirim Sorokin. Dessa maneira, Weber foi incluído em uma larga galeria de sociólogos, cad a um deles representando bem um ponto de vista ou um sistema, ou senão uma determinada doutrina sobre a socied ade. Apesar de concordar com certos aspectos da representação empírica, Germani assumiu uma representação diferente, desenvolvida exemplarmente na época por Talcott Parsons em La Estructura de la A cción Social. Desse modo, argumentou que a observação rigorosa não era suficiente para estabelecer uma disciplina científica contra a visão empirista, mas que era necessário também a existência de um conjunto de pressupostos teóricos independentemente elaborados, que serviriam como guia da observação dos acontecimentos.

Contra a visão pluralistad e Sorokin, Germani viu nessa pluralidade o sinal da imaturidade de uma disciplina e reconheceu, então, a neces- 
sidade de reunir as tradições teóricas divergentes em um esquema sintético e unificado. Foi assim que incluiu os desenvolvimentos metodológicos de Weber como parte desse incipiente mas incessante esforço em direção a uma unificação teórica que, conforme se entendia, tornaria possível o projeto de uma sociologia ao mesmo tempo empírica e analítica.

(Recebido para publicação em outubro de 2004) (Versão definitiva em dezembro de 2004)

\section{NOTAS}

1. A primeira ed ição italiana é de 1962 e a em inglês de 1968 (apesar de em 1947 uma par te da obra ter sido editad a sob o título The Theory of Social and Economic Organization, traduzida por A. M. Henderson e T. Parsons). A edição francesa, que inclui apenas a primeira parte, foi lançada em 1971.

2. Entre eles, constam oito títulos de Max Scheler - p.ex.,El Sabery la Cultura (1926),El Resentimiento de la Moral (1927) e El Puesto del Hom bre en el Cosmos (1929) -; Lujo y Capitalismo (1928), de Werner Sombart; os quatro tomos de Investigaciones Lógicas (1929), de Ed mund Husserl; três obras de Hegel, Filosofía de la H istoria, Fenomenología del Espíritu e Filosofía del Derecho; e, finalmente, de George Simmel, Filosofía de la Coquetería (1924), os seis tomos da Sociología (1927) e Cultura Femenina (1934). Ainda que, finalmente, só editasse um livro, a editora lançou igualmente uma coleção de "Estudos Sociológicos", na qual publicou La Familia (1930), de Ferdinand Lyer Müller.

3. De George Simmel foi editado El Conflicto de la Cultura Moderna, Universidade Nacional de Cór doba, 1923; "Ensa yos Esté ti cos. El Asa. As Ru inas”, Revista de Occidente, 1924; "La Personalidad de Dios", Revist a de Occidente, 1934; "Cultura Femenina y Otros Ensayos" (edição ampliada), Revista de Occidente, 1934; e Schopenhauer e Nietzsche, Beltrán, 1915, que foi posteriormente traduzido por Francisco Ayala na editora Schap ire, em 1944. De Ferdin and Toennies, além de Evolución de la Cuestión Social, editado por Labor em 1927, a Revista de Occidente edita em 1932 "Vida y Doctrina de Thomas Hobbes", e de Hans Freyer "Los Sistemas de la Historia Universal”, em 1931. No ano seguinte, outra editora espanhola, Espasa-Calpe, editou El Despertar de la Humanidad também de Freyer; de Werner Sombart, a Revista de Occidente editou em 1928 "Lujo y Capitalismo" e, em 1931, a editora Labor publicou do mesmo autor La Industria. De Othmar Spann foram publicados três títulos: "Filosofía de la Sociedad ", Revista de Occidente, 1933, "Teorías Principales de la Economía Política", Revista de Occidente, 1934 e "H istoria de las Doctrinas Económicas", Revista de Derecho Privado, 1935. De Alfred Vierkandt, Filosofía de la Sociedady de la His- 
toria, Biblioteca da Universidad Nacional, La Plata, 1934; de Alfred Weber, "La Crisis de la Idea Moderna del Estado en Europa", Revista de Occidente, 1932; e, finalmente, Sociología, Labor, 1932, de Leopold von Wiese.

4. Não pude determinar o sentido da expressão "ideológica" no texto de Levene, mas é possível sup or que a mesma se referia simplesmente - e em oposição ao econôm ico em Marx - às idéias e a seu predomínio na determinação do social, marca que Levene sugeria que deveria ser corrigida com o au xílio de uma sociologia cu ltural nos moldes da que sempre havia sido - segundo Levene - praticada por Durkheim.

5. A referênciad e Treves inclu ía os seis volumes da Pittsburgh Survey, a primeira grande pesquisa sociográfica norte-americana, assim como The Unemployment Survey e The New Survey of Pittsburgh.

6. O ensaio de Germani foi anunciado no primeiro número da revista com o título de "La Sociología Norteamericana", em Minerva.Revista Continental de Filosofía, vol. 1, 1944.

7. Em 1953, dois anos depois de sua edição original, o Fondo de Cultura Económica editou essa obra.

8. Em uma entrevista de alguns anos atrás, Germani confessou o seguinte: "[Por volta dos anos 40] d escobri um tesouro no Instituto de Filosofia da Universidade de Bu enos Aires; seu diretor se interessava, de alguma maneira, pela sociologia e contava com uns cinqüenta livros de autores norte-americanos. Sobre metodologia encontrei Bogardus e Lundberg, encontrei Parsons, La Estructura de la Acción Social, e uma coleção da American Sociological Review, desde o primeiro nú mero, junto com a American Journal of Sociology, a partir de 1935" (Kahl, 1986:55-56).

9. Trata-se de duas resenhas que Germani escreveu a propósito de Fondamenti Logici della Scienza de Abbagnano et alii, Torino, Franceso De Silva, 1947 e, Limiti e Possibilitá della Scienza, Bari, Laterza, 1947, lan çadas na revista Cultura Italiana, ano I, no 2-3, abril/ julho de 1948. 


\section{REFERÊNCIAS BIBLIOGRÁFICAS}

ARGUEDAS, Ledda e LOYO, Aurora. (1979), "La Institucionalización de la Sociología en México", in VVAA, Sociología y Cien cia Política en México (Un Balance de Veinticinco Años). México, UNAM.

ARON, Raymond. (1953), La Sociología A leman a Cont emporánea . Buenos Aires, Paid ós.

AYALA, Francisco. (1947), Tratado de Sociología. Buenos Aires, Losada.

BLANCO, Alejandro. (1998), "Gino Germani: Las Ciencias del Hombre y el Proyecto de una Voluntad Política Ilustrada”. Punto de Vista. Revista de Cultura, no 62.

_ (2003), "Los Proyectos Editoriales de Gino Germani y los Orígenes Intelectuales de la Sociología en la Argentina". Desarrollo Económico. Revist a de Ciencias Sociales, vol. $43, \mathrm{n} \cong \mathrm{o} 169$.

. (2004), "La Sociología: Una Profesión en Disputa", in F. Neiburg e M. Plotkin, Intelectuales y Expertos. Hacia una Sociología Histórica de la Producción de Conocimiento sobre la Sociedad en la A rgentina. Buenos Aires, Paidós.

CUEVILLAS, Fernando. (1950), "Primera Reunión Nacional de Sociología Argentina”. Revista de Estudios Políticos, nํ5, Madrid.

FIGUEROA ROMÁN, Miguel. (1946), Sociografía y Planificación. Universidad Nacional de Tucumán, Tucumán.

FRABOSCHI, Roberto. (1944), “Max Weber, Economía y Sociedad”. Boletín del Instituto de Sociología, no 3, Facultad de Filosofía y Letras, Universidad de Buenos Aires.

GERMANI, Gino. (1946a), "Sociología y Planificación". Boletín de la Biblioteca del Congreso Nacional, $\mathrm{n}$ ㅇ 57, 58 e 59, Buenos Aires.

.(1946b), Teoría e Investigación en la Sociología Empírica. Buenos Aires. Manuscrito inéd ito.

. (1952a), "Sobre Algunas Consecuencias Prácticas de Ciertas Posiciones Metodológicas en Sociología, con Especial Referencia a la Orientación de los Estudios Sociológicos en la América Latina". Boletín del Instituto de Sociología, no 6, Facultad de Filosofía y Letras, Universidad de Buenos Aires.

. (1952b), "Una Década de Discu siones Metodológicas en la Sociología Latinoamericana". Boletín del Instituto de Sociología, no 6, Fa cultad de Filosofía y Letras, Universidad de Buenos Aires.

(1956), "Introdu cción a la Sociometría”, in La Sociología Científica. A puntes para su Fundamentación. México, UNAM.

HIRSCHHORN, Monique. (1988), Max Weber et la Sociologie Française. Paris, L’Harmat$\tan$.

KAHL, Joseph A. (1986), “Gino Germani: Modernización”, in Tres Sociólogos Latinoamericanos. México, UNAM.

KÄSLER, Dirk. (1988), “The Reception of Weber's Work during his Lifetime”, in M. Weber: An Introduction to his Life and Work. Cambridge, Polity Press.

KIVISTO, Peter e SWATOS JR., William H . (1988), M ax Weber. A Bio-Bibliography. New York, Greenwood Press. 
LEVENE, Ricardo. (1934), "Prólogo", in A. Vierkandt, Filosofía de la Sociedad y de la Historia. Buenos Aires, Biblioteca de la Universidad Nacional de la Plata.

. (1942), "El Instituto de Sociología de la Facu ltad de Filosofía y Letras". Boletín del Instituto de Sociología, no 1, Facultad de Filosofía y Letras, Universidad de Buenos Aires.

LIMA, Antonio Car los de Sou za. (1987), As Tra duções d a Obra de Max Weber no Brasil. Elementos para Reflexão. Museu Nacional, Universidade Federal do Rio de Janeiro. Manuscrito.

LÓPEZ CAMPILLO, Evelyne. (1972), La Revista de Occidente. Madrid, Taurus.

MEDINA ECHAVARRÍA, José. (1940), Panorama de la SociologíaContemporánea. México, La Casa de España en México. (1941), Sociología: Teoría y Técnica. México, Fond o de Cultura Económica. (1992), "Nota Preliminar de la Primera Edición en Español”, in M. Weber, Economía y Sociedad. México, Fondo de Cultura Económica.

ORGAZ, Raúl. (1932a), La Cien cia Social Contemporánea. Buenos Aires, Cabut y Cia. (1932b), "El Problema de la Realidad de lo Social". Cursos y Conferencias, n 12. (1950), Sociología. Obras Completas. Córdoba, Assandri.

PARSON S, Talcott. (1928), "Capitalism in Recent German Literature: Sombart and Weber". Journal of Political Economy, vol. 36.

. (1929), "Capitalism in Recent German Literature: Sombart and Weber". Journal of Political Economy, vol. 37.

. (1970), “On Building Social System Theory: A Personal History”. Daedalus, vol. 99, no 4 .

PLATT, Jennifer. (1996), "Scientism", in A History of Sociological Research Methods in America 1920-1960. Cambridge, Cambridge University Press.

POLLAK, Mich ael. (1986), "Max Weber en France. L’Itinéraire d 'une Oeuvre”. Cahiers de 1’I.H.T.P, vol. 3.

POVIÑA, Alfredo. (1933a), "La Sociología Relacionista”. Cursos y Conferencias, no 8 . (1933b), "La Sociología Relacionista". Cursos y Conferencias, n으 12.

(1939), La Sociología como Ciencia de la Realidad. Determinación de su Concepto en Freyer. Córdoba, Universidad Nacional de Córdoba.

. (1941a), La Metodología Sociológica de Max Weber. México, Fond o de Cultura Económica.

(1941b), Historia de la Sociología en Latinoamérica. México, Fond o de Cultura Económica.

REYNA, José Luis. (1979), "La Investigación Social en México”, in VVAA, Sociología y Ciencia Política en México (Un Balance de Veinticinco Años). México, UNAM.

ROMERO, Francisco. (1952), "Indicaciones sobre la Marcha del Pensamiento Filosófico en la Argentina”, in Sobre la Filosofía en América. Bu enos Aires, Raigal. 


\section{Alejandro Blanco}

SCHMIDT-KOCH, Ria. (1935), Filosofía Alemana Traducida al Español. Buenos Aires, Sociedad Kantiana.

SCHROETER, Gerard. (1980), "Max Weber as Outsider: His Normal Influence on German Sociology in the Tw enties". Journal of the History of the Behavioral Sciences, vol. $16, \mathrm{n} \div 4$.

SHILS, Edward. (1970), "Tradition, Ecology and Institution in the History of Sociology". Daedalus, vol. 99, no 4 .

SOROKIN, Pitirim. (1928), Contemporary Sociological Theories. Cambridge, MA, Harvard University Press.

TOULMIN, Stephen. (1974), "From Form to Function: Philosophy and History of Science in the 1950 and Now". Daedalus, vol. 103, no 1 .

TREVES, Renato. (1941), Sociología y Filosofía Social. Buenos Aires, Losada. . (1942), Introducción a las Investigaciones Sociales. Tucumán, Universidad Nacional de Tucumán.

VILLAS BOAS, Glau cia. (1994), “A Recepção da Sociologia Alemã no Brasil. Notas para uma Discussão”. Série Estudos Ciências Sociais, no 11, IFCS/ UFRJ.

ZABLUDOVSKY, Gina. (2002), "La Emigración Republicana Española y el Pensamiento Alemán en México: La Traducción de Economía y Sociedad". Revista Mexicana de Ciencias Políticas y Sociales, $\mathrm{n} \cong \mathrm{3}$. 


\section{APÊNDICE}

\section{CIRCULAÇÃO E DIFUSÃO EDITORIAL: BREVE CRONOLOGIA}

\section{1) Obras de Max Weber}

\section{1a) Editadas na Argentina}

1966: El Sabio y la Política, Córdoba, Eudecor.

1973: Ensayos sobre Metodología Sociológica, Bu enos Aires, Amorrortu.

1977: ¿Qué Es la Burocracia?, Buenos Aires, La Pléyade.

1977: Estructuras de Poder, Buenos Aires, La Pléyade.

1978: Sociología de la Religión, Buenos Aires, La Pléyade.

\section{1b) Editadas na Espanha e no México}

1926: "La Decadencia de la Cultura Antigua", Revista de Occidente, tomo XII, no 37, Madrid.

1942: Historia Económica General, México, Fondo de Cultura Económica.

1944: Economía y Sociedad, México, Fond o de Cultura Económica.

1955: La Ética Protestante y el Espíritu del Capitalismo, Revista de Derecho Privado, Madrid.

1967: El Político y el Científico, Madrid, Alianza.

1971: Sobre la Teoría de las Ciencias Sociales, Barcelona, Península.

1972: Ensayos de Sociología Contemporánea, Barcelona, Planeta-Agostini, 2 vols.

1982: Escritos Políticos, México, Folios. 


\section{2) Obras referentes a Max Weber}

\section{2a) Editadas na Argentina}

1941: Alfredo Poviña, La Metodología Sociológica de Max Weber, Córdoba, Imprenta de la Universidad Nacional de Córdoba.

1953: Raymond Aron, La Sociología Alemana Contemporánea, Buenos Aires, Paidós.

1970: Reinhard Bendix, Max Weber, Buenos Aires, Amorrortu.

1970: Raymond Aron, Las Etapas del Pensamiento Sociológico, Buenos Aires, Siglo XX, 2 vols.

1970: Irving Zeitlin, Ideología y Teoría Sociológica, Buenos Aires, Amorrortu.

1971: Talcott Parsons et alii, Presencia de Max Weber, Buenos Aires, Nueva Visión.

1972: Ju dith Janoska-Bendl, Max Weber y la Sociología de la Historia, Buenos Aires, Editorial Sur.

1977: Juan Carlos Portantiero, La Sociología Clásica: Durkheim y Weber, Buenos Aires, Centro Editor de América Latina.

\section{2b) Editadas na España}

1966: J. Peter Mayer, Max Webery la Política Alemana, Madrid, Instituto de Estudios Políticos.

1967: Julien Freund, Sociología de Max Weber, Barcelona, Península.

1968: Talcott Parsons, La Estructura de la Acción Social, Madrid, Guadamarra.

1972: Jean-Marie Vincent, La Metodología de Max Weber. Fundamentos Metodológicos, Barcelona, Península.

1976: Anthony Giddens, Política y Sociología en Max Weber, Madrid, Alianza.

1978: Juan Francisco Marsal, Conocer Max Webery su Obra, Barcelona, Dopesa. 


\begin{abstract}
Max Weber in Argentine Sociology (1930-1950)

The thinking of Max Weber became known in the Argentina academic community in the years preceding the first translations of his General Economic History and Economy and Society into Spanish, published by Fondo de Cultura Económica in 1942 and 1944, respectively. The first Argentine references to Weber's work appear in the early 1930s in an intellectual context marked by the revolt against Positivism and the spread of German thinking in general and German sociological thinking in particular. Throughout that period, sociology was an emerging field and sociologists faced the task of justifying their practice and approaches. Nevertheless, there were different views of the discipline, each of which articulating a specific interpretation of Weber's thinking.
\end{abstract}

Key words: Max Weber; sociology; Argentine sociology

\title{
RÉSUMÉ
}

Max Weber dans la Sociologie A rgentine (1930-1950)

La pensée de Max Weber est devenue connue chez les intellectuels argentins dans les années précédant les premières traductions en espagnol de ses textes. HistoriaEconóm ica General et Economía y Sociedad, tou s deux parus chez Fondo de Cultura Económica respectivement en 1942 et 1944. Les premières références à l'œuvre de Weber surgissent au début des années 1930 dans un milieu intellectuel marqué par la révolte contre le positivisme et la diffusion de la pensée allemande en général, et la pensée sociologique de Weber, en particulier. Pendant toute cette période, la sociologie en était à ses balbutiements et les sociologues s'attaquaient à la tâche de justifier leur pratique et les approches qu'ils effectuaient. Il y avait, pourtant, différentes conceptions de la discipline, chacune d'entre elles proposant une interprétation particulière de la pensée webérienne.

Mots-clé: Max Weber; sociologie; sociologie argentine 